\title{
Mulher, Negra e Repórter: atravessamentos entre gênero, raça, subjetividade e telejornalismo na trajetória de Glória Maria.
}

\section{Women, Black and Reporter: entaglements of gender, Race, subjectivity and television journalism in the trajectory of Glória Maria.}

\section{Valéria Vilas Bôas}

É professora da Universidade Federal de Sergipe. Doutora pelo Programa de Pósgraduação em Comunicação e Cultura Contemporâneas da UFBA, com doutorado sanduíche realizado na Université Lumière Lyon 2 (França). É pesquisadora do Lavint/UFS e pesquisadora associada do Tracc/UFBA.

\section{RESUMO}

A proposta deste artigo é discutir a relação entre feminismo e democracia a partir da observação de como transformações nas práticas convencionais do jornalismo deixam ver um cenário mais amplo de mudanças estruturais em nossas organizações sociais e políticas. A partir da observação da trajetória de Glória Maria como repórter, buscamos acessar atravessamentos entre subjetividade, jornalismo, raça e gênero. Argumentamos que a noção de objetividade jornalística opera como modo de regulação de expressões subjetivas a partir de uma articulação de sentido entre corpos convencionados como sóbrios, discretos e os valores de credibilidade e autoridade a eles confiados.

PALAVRAS-CHAVE: telejornalismo; raça; gênero; Glória Maria.

\section{ABSTRACT}

The purpose of this article is to discuss the relationship between feminism and democracy based on the observation of how transformations in the conventional practices of journalism reveal a broader scenario of structural changes in our social and political organizations. From the observation of Glória Maria's trajectory as a reporter, we seek to access crossings between subjectivity, journalism, race and gender. We argue that the notion of journalistic objectivity operates as a way of regulating subjective expressions based on an articulation of meaning between 
bodies agreed to be sober, discreet and the values of credibility and authority entrusted to them.

KEYWORDS: television news, race, gender, Glória Maria.

\section{RESUMEN}

El propósito de este artículo es discutir la relación entre feminismo y democracia a partir de la observación de cómo las transformaciones en las prácticas convencionales del periodismo revelan un escenario más amplio de cambios estructurales en nuestras organizaciones sociales y políticas. A partir de la observación de la trayectoria de Glória Maria como reportera, buscamos acceder a los cruces entre subjetividad, periodismo, raza y género. Argumentamos que la noción de objetividad periodística opera como una forma de regular las expresiones subjetivas a partir de una articulación de significados entre cuerpos acordados para ser sobrios, discretos y los valores de credibilidad y autoridad que se les confían.

PALABRAS CLAVE: informativos de television; raz;, g éner;, Gloria Maria.

Este artigo propõe uma reflexão sobre a relação entre feminismo e democracia a partir da observação de como transformações nas práticas convencionais do jornalismo deixam ver um cenário mais amplo de mudanças estruturais em nossas organizações sociais e políticas. Para tanto, o nosso olhar se volta para a trajetória da repórter Glória Maria na tentativa de acessar atravessamentos entre subjetividade, jornalismo, raça e gênero. Aparecendo no vídeo da televisão brasileira desde 1971, Glória Maria tem quase cinquenta anos de carreira como jornalista da TV Globo - a maior emissora de tevê do Brasil - e já no final dos anos 1970 se destaca em um ambiente ainda dominado pela presença masculina e branca.

Mulher e negra, Glória ocupa uma posição bastante singular no cenário do jornalismo televisivo brasileiro, mas sua imagem pública de repórter durante muito tempo, especialmente naquele momento inicial, remete muito pouco a esses dois traços definidores, eclipsados pela construção de uma ideia de objetividade jornalística que separa discursivamente jornalista e sujeito. Ao longo do tempo, a sua atuação foi se transformando a ponto de, contemporaneamente, ser marcada por uma performance menos convencional na qual sua ação pessoal na cena da 
reportagem passa a ser constituidora da própria narrativa jornalística1 ${ }^{1}$ Em nossa observação identificamos, contudo, que, ao longo de sua trajetória, a experiência subjetiva do feminino e da negritude não são configuradas enquanto possibilidade de partilha e reconhecimento na figura da jornalista que, na cobertura de uma chacina de crianças negras, por exemplo, destaca a sua comoção na relação com a função profissional, com o ter estado ali que permite ao jornalista um contato com os fatos.

\section{A convenção de linguagem como operação de poder}

O Brasil é um país em que a permanência e reprodução de situações de pobreza e exclusão sociais tem as desigualdades de gênero e raça como eixos estruturantes de sua matriz. Localizando o telejornalismo como parte de um sistema opressivo que interpela os sujeitos também a partir de aspectos subjetivos como raça e classe, acreditamos que é na construção que legitima lugares possíveis de reconhecimento do outro que ele silencia e amplia, por exemplo, a legitimação da indignação seletiva, da indignação merecida apenas por aqueles que podemos reconhecer enquanto sujeito. Assim, os modos como o jornalismo televisivo constrói, por exemplo, sua linguagem padrão e objetiva, dialoga com formações socioculturais e históricas mais amplas de rejeição institucionalizada da diferença através das quais, como destaca Audre Lorde,

(...) todos nós fomos programados para reagir com medo e ódio às diferenças humanas e a lidar com essas diferenças de determinada maneira dentre três: ignorá-las e, se isso não for possível, imitá-las se acharmos que são dominantes, ou destruí-las se acharmos que são subordinadas. (Lorde, 2019, p. 240).

Entendemos, seguindo também Judith Butler (2004), que o poder consegue se impor sob a forma de sujeição por se apropriar de um princípio de abertura que

1 Essa sua atuação contemporânea tem encontrado eco e repercussão também nas redes sociais e no modo como seus usuários se apropriam de produtos e imagens midiáticas para a produção de gifs, memes e paródias diversas. Destacamos, por exemplo, a existência de páginas como "Glória Maria Espiã Sensual" (https://pt-br.facebook.com/gloriamariaespia/) que apresenta fotos da repórter em diversas aparições públicas como supostas provas de que ela seria "uma espiã sem idade”, ou “Gifs Glória Maria” (https://twitter.com/gifsgloriamaria), que produz paródias em imagens animadas a partir de vídeos da jornalista. Para fins deste artigo, contudo, vamos nos concentrar na trajetória televisiva da repórter. 
constitui todo e qualquer sujeito e o melancoliza, o faz aceitar ser habitado por um discurso que não é seu, mas o constitui. Se a nossa relação com o outro e a própria condição de que o outro nos reconheça enquanto sujeito são mediadas pela linguagem, pelas convenções, pela sedimentação das normas, a representação do humano é também condicionada por nossos quadros de referência, dos quais o jornalismo faz parte. Nesse sentido, abordar os atravessamentos entre subjetividade, jornalismo, raça e gênero a partir da trajetória de uma jornalista negra nos parece um modo de tentar compreender como as relações de poder raciais e de gênero conformam nossas sociedades e culturas também através do jornalismo televisivo e de suas formas.

Argumentamos, sobretudo em relação à performance convencionada do repórter de televisão, que a construção de sentidos sobre questões de raça, gênero e classe constituem um lugar de problema importante para uma abordagem supostamente objetiva do telejornalismo. No caso das disputas em torno do lugar do feminino no jornalismo brasileiro, para além de um contexto que marca a entrada de mulheres no mercado de trabalho, em torno dos anos 1980, representado pelo aumento no número de mulheres repórteres presentes no vídeo, existe também uma tensão na divisão supostamente estabelecida entre uma esfera pública racional a partir da qual são feitas deliberações em torno dos assuntos de interesse social e político e uma esfera privada reservada às questões domésticas, cotidianas e afetivas - tradicionalmente entendidas no jornalismo como menos importantes.

Consideramos que o jornalismo, enquanto uma instituição que se desenvolve em culturas específicas, estabelece convenções que representam uma possibilidade do fazer jornalístico e que estão em diálogo constante com mudanças mais amplas na história das culturas e sociedades. Ainda que consideremos o jornalismo hegemônico a partir das disputas implicadas em sua definição, ainda que consideremos que o conceito de objetividade, por exemplo, tem sido constantemente rediscutido e questionado enquanto uma prática de fato possível, essa disputa é geralmente localizada em relação a uma definição de jornalismo que valoriza a racionalidade, o debate público que orientaria o cidadão ao voto, a fazer escolhas econômicas acertadas. Assim, os sujeitos privados aos quais o jornalismo 
costuma se referir são também definidos em uma relação que se estabelece pela noção de propriedade, constituindo sujeitos como indivíduos que têm, entre seus principais direitos, o de manter a sua vida particular para si. As emoções, por exemplo, entendidas nesse contexto como algo altamente privado e pessoal, são então frequentemente tratadas como algo que deveria estar fora do debate público e vistas como a marca de um problema jornalístico associado à tabloidização, como aponta Phillipa Chong (2017).

Destacamos que do ponto de vista sociopolítico, reconhece-se que as lutas feministas têm transformado as relações entre público e privado ao colocar, por exemplo, a violência doméstica - entendida, por exemplo, pelo clássico argumento de que "em briga de marido e mulher não se mete a colher" como algo da esfera privada e pessoal - como pauta pública (Carneiro, 2019). No jornalismo, à medida que mulheres passam a ocupar espaços tradicionalmente dominados pela presença masculina, o modo como os sujeitos femininos se conformam exibe uma tensão entre a adequação a uma postura convencionalmente reconhecida como masculina - pela recorrência ao uso de tailleur, cabelos curtos, pouco uso de acessórios que configuram o sentido de seriedade e credibilidade dominantes à época - e a convocação, ainda que pela sua simples existência naquele contexto, de uma esfera de valores e sentidos relacionados aos seus papéis sociais como mãe e mulher. Assim, a abordagem que propomos do jornalismo parte de uma perspectiva que considera o modo como subjetividades descentradas e múltiplas dos sujeitos produtores de notícias revelam a si mesmas e a disputas de poder que atravessam sua constituição nas performances de atuação desses repórteres no vídeo.

\section{Ao vivo e a cores}

A presença visual de repórteres nas imagens do jornalismo televisivo não é comum nos primeiros anos de existência do meio no país. Contudo, nas raras vezes em que um repórter aparece em programas como Repórter Esso ou Jornal Diário de São Paulo, ambos da TV Tupi, ele é do gênero masculino, em consonância com um momento histórico dos anos 1950 e 1960 em que as mulheres ainda não são uma presença maciça no mercado de trabalho de modo mais amplo - sobretudo em profissões com destacado reconhecimento social. Destacamos a questão do 
reconhecimento social salientando que, como indica Maria Cristina Aranha Bruschini (2007, p.542), mesmo ao longo dos anos 1970 e 1980, “o trabalho doméstico realizado no domicílio pelas donas de casa não era sequer contabilizado como atividade econômica".

Estudos apontam que no Brasil - país que explorou oficialmente a mão de obra de negros escravos até o final do século XIX - as mulheres negras apresentam uma situação de dupla desvantagem sistemática em todos os indicadores sociais e de mercado de trabalho. (Abram, 2006; Sanches, 2009; Bruschini \& Lombardi, 2002) Assim, no contexto das mulheres negras, o apagamento de sua identidade profissional se faz ainda presente seja pela operação de apagamento do trabalho doméstico como um trabalho produtivo, seja pela manutenção de estruturas de hierarquia de classe que continua lhes atribuindo espaços e papéis que lhes foram atribuídos desde a escravidão (Nascimento, 2019). Como analistas, destacamos a necessidade de pensar que as convenções do jornalismo são também construídas como um lugar de regulação e violência dos corpos e das subjetividades dos sujeitos repórteres, dos sujeitos cujo discurso é apropriado pelo jornalismo como fonte e dos sujeitos espectadores convocados como um terceiro elemento do diálogo.

Nesse cenário sociocultural e midiático, a trajetória de Glória Maria como repórter é singular. Simbolicamente, Glória "foi a repórter que entrou no ar ao vivo, na primeira matéria a cores do Jornal Nacional, em 1977, mostrando o movimento de saída de carros do Rio de Janeiro, em um fim de semana"2, e uma cor de pele pouco frequente naquele espaço. Também em relação ao gênero, a atuação de Glória configurava exceção. Mesmo em um momento de atuação feminina mais consolidada no mercado de trabalho formal, a figura do repórter de televisão é ainda majoritariamente masculina no final dos anos 1970 como nos dá indícios a crítica de Arthur da Távola, de maio de 1979 sobre a maior presença visual de repórteres no meio:

Cid Moreira, Carlos Campbell, Celso Freitas (aquele de São Paulo que tem pinta de ter ganho, em criança, um primeiro prêmio de robustez infantil), dois repórteres paulistas cujos nomes me

2 Perfil da repórter feito pelo site de Memória da Globo disponível em: <https://memoriaglobo.globo.com/perfil/gloria-maria/>

Dossiê Crise, Feminismo e Comunicação - https://revistaecopos.eco.ufrj.br/ 
escaparam; o repórter Ricardo Pereira de Brasília e a repórter Glória Maria, do Rio. Sete profissionais para 12 notícias, sete profissionais envolvidos, só no tocante a vídeo. (TÁVOLA, 1979)

Ainda que o material audiovisual de acervo sobre o início da televisão seja escasso, uma busca nas bases existentes de acervo no Brasil ${ }^{3}$ não indicam qualquer traço de atuação de mulheres no vídeo ou em sua produção e, mesmo em 1979, quando Arthur da Távola cita o aumento do número de repórteres visualmente representados no Jornal Nacional, Glória Maria é a única mulher entre sete repórteres. No vídeo mais antigo que localizamos da repórter ${ }^{4}$, uma passagem de matéria que foi ao ar no Jornal Nacional em 1976, a imagem da jovem repórter de cabelos black power e sobreposição de blusas de cores contrastantes, na rua, se mostra naturalmente após a chamada da matéria feita do estúdio por Cid Moreira, de terno e gravata em cores claras e discretas. Também em uma reportagem que foi ao ar em 1981, relembrando os 10 anos do acidente no viaduto Paulo de Frontin que, inclusive, marcou a estreia de Glória no trabalho como repórter - é curioso observar que ainda que sua postura seja reconhecível a partir de convenções que moldam ainda hoje a performance do repórter de tevê, os códigos de vestimenta que operam naquele momento são bastante flexíveis: Glória mantém o cabelo black power, veste uma blusa branca decotada com colares, pulseiras e brincos pendentes à mostra e um cinto grosso feito de tecido semelhante ao da blusa. Em uma participação no programa Mais Você em que foi exibido um vídeo ${ }^{5} \mathrm{com}$ momentos de sua carreira, Glória salienta

eu comecei em uma época em que o telejornalismo tava começando. Eu cheguei na Globo tinha o Jornal Nacional, o Jornal Amanhã que era o Jornal da Globo e assim, o repórter não aparecia no vídeo. A gente fazia as matérias e o Cid Moreira e o Ségio Chapelin narravam e a gente só às vezes fazia uma pergunta, não tinha o repórter aparecendo, entrevistando, não. (...) Só uns

3 É possível encontrar material audiovisual dos primeiros anos da tevê brasileira nos acervos históricos disponíveis no site da Cinemateca Brasileira [http://www.bcc.org.br/] e no Arquivo Nacional no Rio de Janeiro. Além disso, há material disponibilizado online em acervos pessoais ou institucionais como o Memória Globo [http://memoriaglobo.globo.com/].

4 O vídeo faz parte de uma compilação de momentos apresentada por ocasião da participação de Glória Maria no programa Mais Você, também da Rede Globo, e pode ser visto em $<$ https://globoplay.globo.com/v/5731560/>. Acesso em 29. ago. 2020.

5 O vídeo de participação da jornalista no programa pode ser visto no link: <https://globoplay.globo.com/v/5731560/>. Acesso em 29. ago. 2020. 
quatro anos depois que eu já estava no jornalismo é que a gente começou a aparecer no ar. Isso eu acho que fez uma geração de jornalistas bem diferente porque a gente foi ensinado a cultuar a matéria, a história, não tinha aquela coisa do ego de você botar a cara no ar pras outras pessoas te verem. Ou você fazia um trabalho excepcional para ser lido pelo Cid e pelo Sérgio, ou então você não fazia nada.

Ao mencionar as condições de trabalho em que ingressa na emissora, Glória parece nos deixar ver uma dinâmica em que sua passagem para o vídeo parece justificada pela demonstração de um trabalho de excelência que a qualifica como repórter em uma época em que o trabalho televisivo não tinha ainda convenções muito definidas. Tendo isto em conta, nos parece interessante retomar uma discussão de Beatriz Nascimento (2019) sobre a mobilidade feminina no mercado de trabalho. A autora salienta que no momento em que mulheres brancas passaram a ocupar cargos em empregos burocráticos de baixo nível, como secretárias e recepcionistas, por exemplo, além da barreira da qualificação educacional à qual mulheres negras tinham pouco acesso, a implicação de relações públicas que havia nesses cargos era também um empecilho já que "neste contexto, o critério racial se faz muito mais seletivo, mantendo a mulher negra nos empregos tradicionais ou, então, como operárias industriais" (Nascimento, 2019, p. 262).

Sobre o culto à imagem que foi-se estabelecendo à medida que a figura do repórter tornou-se mais comum na tela e que a linguagem televisiva convencionouse de modo mais inflexível, é interessante observar uma fala da jornalista em uma matéria publicada pela Revista Veja, em 1994:

Não se pode dizer que seja uma situação de igualdade plena. É só fazer um exame estético no elenco masculino e feminino. Não se exige dos homens que tenham porte atlético nem perfil de Antonio Banderas. Basta que sejam apresentáveis. Para as mulheres, beleza continua sendo um dado essencial. 'Antes, as redes diziam que mulheres não tinham credibilidade', conta Glória Maria, repórter do Fantástico, 23 anos de profissão. 'Decidiram inovar colocando mulheres, para dizer que não há machismo. Mas as feias não têm vez. É sempre um mesmo padrão. Loira de olhos azuis e morena de cabelo curtinho.' (Sanches, 1994, p. 93)

A regra de apresentação de repórteres televisivos nos anos 1990 indicava a necessidade de um texto correto, uma voz empostada sem exageros ou sotaques 
regionais, uma imagem discreta que não se sobressaísse à notícia. A figura feminina da repórter de televisão aproximava-se de padrões estéticos cuja referência costumava ser masculina: cabelos curtos, assessórios e maquiagem discretos, tailleur como vestimenta alternativa ao terno. Assim, o que o que se convencionou como a performance padrão obedecia a critérios que dialogavam não apenas com padrões de qualidade jornalística, como também, com padrões de uma imagem pessoal que pudesse ser também reconhecida como credível e objetiva. Sobre esse contexto, a declaração de Glória na matéria citada acima é bastante significativa e dá indícios de que a essa altura, a disputa em torno da figura feminina e seus modos de apresentação no jornalismo de televisão praticamente silencia questões de raça.

A cobertura feita pela Globo sobre a Chacina da Candelária, em julho de 1993, em que oito crianças e adolescentes negros em situação de rua foram assassinadas, traz uma atuação da repórter que, ao mesmo tempo que exibe marcas de uma implicação pessoal no relato, apaga a discussão sobre racismo. Glória Maria relata o fato para o Jornal Nacional a partir de um ponto de vista bastante particular: o fato de ela ter conhecido alguns dos meninos assassinados enquanto fazia uma reportagem para o Fantástico dias antes. Na matéria, disponível no site Memória Globo ${ }^{6}$, a repórter, posicionada em frente à Igreja onde aconteceu a chacina em que policiais militares do Rio de Janeiro assassinaram oito jovens em situação de rua, fala o seguinte texto:

Três dias atrás eu estava exatamente aqui nesse lugar em frente à Igreja da Candelária aqui no Centro do Rio, entrevistando meninos de rua, para fazer uma reportagem sobre solidariedade. É, solidariedade, uma palavra, que eles não tiveram tempo de conhecer. (...) Eles estavam assim, alegres, debochados, rebeldes, verdadeiros meninos de rua e falaram de suas esperanças (...). Mas os sonhos foram cortados por tiros, disparos que no meio da noite, acabaram com tantas vidas. Dos meninos da candelária que eu conheci pelo menos estes três foram assassinados. Por enquanto, eles não têm nome, ainda não foram identificados. Este era considerado o líder do grupo.

6 Vídeo disponível através do link < https://memoriaglobo.globo.com/jornalismo/coberturas/chacina-na-candelaria/>. Acesso em 29. ago. 2020

Dossiê Crise, Feminismo e Comunicação - https://revistaecopos.eco.ufri.br/ 
É importante destacar que a reportagem que Glória Maria preparava enquanto esteve com os meninos da Candelária iria ao ar no Fantástico, programa com uma relação mais flexível com o jornalismo, enquanto o relato mencionado acima foi ao ar no Jornal Nacional, que, por ter se tornado o principal telejornal do país em relação à audiência foi-se consolidando também como grande referência em relação à convenção da forma do telejornal. A matéria, que começa com uma passagem da repórter, é na sequência ilustrada por imagens gravadas no dia a que ela se refere, quando esteve com os garotos gravando uma reportagem, três dias antes da chacina. Dessas imagens são retirados destaques de imagens dos garotos assassinados que Glória cita e a matéria se encerra com duas sonoras, a de um dos meninos assassinados, identificado como líder do grupo, e de uma menina sobrevivente. Ainda que apresentados sem nome, esses garotos têm suas falas incluídas na matéria, falam de sua esperança de melhorar, de sair da rua, de que seus companheiros estejam na escola, de ter uma casa e ser feliz. Mas embora o enquadramento ali seja feito pela presença da repórter no local com eles, antes do assassinato, em nenhum momento ela aparece fisicamente nas imagens que já haviam sido gravadas, para além de uma mão que segura o microfone.

Nos interessa observar, contudo, que ainda que a forma convencional de apresentação do repórter seja respeitada - e que a autenticação da reportagem dialogue com ela pela valorização das sonoras, da passagem com microfone da emissora em punho, e da própria presença da repórter e da equipe de reportagem numa relação com o fato ainda que não o tenham presenciado -, Glória Maria, enquanto investida de sua função de repórter, pôde testemunhar uma situação que veio a ter, pouco tempo depois da sua atuação enquanto repórter sobre ela, um desfecho trágico. Assim, o que enquadra o modo como a chacina é noticiada nesse fragmento é justamente a figura da repórter, mas unicamente enquanto repórter e nesse sentido o 'eu' presente ali é um 'eu' identificado com a profissão e cuja figura pessoal, com suas marcas raciais, de gênero, suas emoções em relação ao ocorrido, ainda que em certa medida sejam visíveis, são apagadas enquanto parte da construção jornalística. Em nenhum momento, por exemplo, o fato de Glória Maria ser negra como aquelas crianças em um país onde os assassinatos de pessoas negras tem uma proporção muito mais alta que o assassinato de pessoas 
brancas ${ }^{7}$, é chamado em causa ou coloca questão para a construção noticiosa. A experiência subjetiva da negritude não é configurada enquanto possibilidade de partilha e reconhecimento na figura da jornalista que coloca a sua comoção na relação com a função jornalística, com o ter estado ali que permite ao jornalista um contato com os fatos. Na verdade, a questão racial não é, efetivamente, relacionada ao crime na cobertura feita pelo noticiário.

A temática do feminino, contudo, aparece no material apresentado pela Globo em seu site de memória como parte da cobertura da chacina em dois momentos que remontam à figura da mulher como mãe. No primeiro deles ${ }^{8}$, Sônia Bridi, primeira repórter a chegar ao local, relata sua memória da cobertura convocando, justamente, a sua experiência materna como articuladora do seu trabalho:

eu fiz uma passagem pro Jornal Hoje e que era muito indignada, eu tinha acabado de ver criança de seis anos com uma bala na cabeça, como é que eu podia não tá indignada com aquilo, da idade da minha filha que não era nem alfabetizada direito. Como é que eu não posso ficar indignada com aquilo? E alguém me disse assim: 'ah, cortou o mal pela raiz' - como é que eu posso ouvir uma coisa dessas imparcial? (...) Então eu fiz uma passagem muito indignada, como é que ninguém viu? Os maiores bancos ali, tudo ao redor, cheio de vigia, como é que ninguém viu nada? Como é que aquilo vira terra de ninguém? E era mais ou menos esse tom a minha passagem.

Em um segundo momento, a reportagem de Marcelo Canelas mostra mães chegando à Candelária em busca de seus filhos. Ali, o pavor dessas mulheres de que eles estejam entre os assassinados é o que dá partida à pauta. Nas três reportagens, o lugar de mulher parece ser tomado como um lugar de humanização dessas crianças, são elas que estiveram com eles, lhes entrevistaram, chegaram logo após

7 O atlas da violência de 2017 indica que "De cada 100 pessoas que sofrem homicídio no Brasil, 71 são negras. (...) De fato, ao se analisar a evolução das taxas de homicídios considerando se o indivíduo era negro ou não, entre 2005 e 2015, verificamos dois cenários completamente distintos. Enquanto, neste período, houve um crescimento de $18,2 \%$ na taxa de homicídio de negros, a mortalidade de indivíduos não negros diminuiu 12,2\%. Ou seja, não apenas temos um triste legado histórico de discriminação pela cor da pele do indivíduo, mas, do ponto de vista da violência letal, temos uma ferida aberta que veio se agravando nos últimos anos." (CERQUEIRA et al. 2017, p. 30-31)

8 Vídeo disponível no link <http://globotv.globo.com/rede-globo/memoriaglobo/v/depoimento-sonia-bridi-chacina-na-candelaria-1993/4116998/>

Dossiê Crise, Feminismo e Comunicação - https://revistaecopos.eco.ufrj.br/ 
eles terem visto seus amigos serem assassinados e representam ainda, na figura das mães, um elo dessas crianças com algo que possa ser reconhecido como família. Esse lugar de mulher aparece ainda na figura da artista plástica e socióloga Ivone Melo, que trabalhava com as crianças e foi chamada por eles logo após a chacina. Mesmo que regulada pela norma jornalística e que construída a partir de um lugar-comum que relaciona o feminino à família e às crianças, a presença de repórteres mulheres parece operar no sentido de humanizar as crianças e chamar atenção para um sentido de acolhimento necessário. Esse acolhimento, contudo, não é configurado - ao menos no conjunto de matérias selecionadas pela própria emissora como constituidores da memória a respeito da cobertura do fato - como abertura para a discussão, por exemplo, do papel das mulheres como chefes únicas de famílias não por escolha, mas em relação a contextos de pobreza e abandono ligadas, majoritariamente, a uma herança racial da escravidão. A apropriação do feminino aqui parece também remeter-nos a um lugar-comum de dicotomia, um reforço da separação entre o doméstico e o público, a responsabilidade a respeito da família como algo que não pertence ao homem, à esfera que se reveste de valores masculinos e se entende pública.

\section{Uma repórter cuja ação é constituidora da construção jornalística}

A expressão de sobriedade que configurava o jornalismo televisivo em seu momento de consolidação e que perdura ainda enquanto forma hegemônica pela qual ele se legitima, estava afinada também a um projeto de busca de qualidade na linguagem televisiva. Igor Sacramento (2008) ressalta, por exemplo, que parte do movimento de mudança na programação televisiva após o acordo firmado com os governos militares para autocensura de conteúdos considerados inapropriados, mais especificamente entre os anos de 1965 e 1980, foi o de substituir programas de maior apelo popular, como os programas de auditório, por programas jornalísticos. Como aponta o autor,

Se agruparmos os programas dos gêneros descritos em três grupos (entretenimento, dramaturgia e informação), enxergaremos outras questões acerca da mudança de perfil na programação da TV Globo. [...] Em busca da qualidade, houve uma diminuição no investimento em programas de entretenimento, 
uma certa estabilidade nos de dramaturgia e um crescimento nos de informação. É importante destacar que a queda dos programas de entretenimento é o maior número absoluto (20\%) do que qualquer outra ampliação. (Sacramento, 2008, p. 102-103)

Segundo Sacramento, o investimento no telejornalismo diz também de uma resposta positiva por parte da crítica televisiva: "A associação do uso do mais avançado aparato técnico existente à época como garantia de qualidade foi defendida pelos jornais. Nesse sentido, a 'boa' utilização da linguagem audiovisual e das novas tecnologias de comunicação proporcionariam 'em si mesmas' uma certa distinção dos programas na grade de programação" (Sacramento, 2008, p.105). É na expressão de um jornalismo que atende tanto a exigências institucionais de um governo que precisava fornecer informações controladas a seus cidadãos como forma de conter a intranquilidade pública e manter a segurança nacional, quanto a uma demanda de padrão de qualidade, que a televisão encontra um modo de legitimar a sua existência e firmar-se enquanto um meio de comunicação de grande abrangência.

Apesar do avanço na conformação da sobriedade como regra máxima de atuação de repórter para sustentar o ideal de objetividade dos telejornais, a atuação de Glória Maria, contudo, sempre teve como marca uma expressão pessoal muito particular. Se nas passagens de 1976 e 1981 o que soava como disruptivo em relação ao padrão era a sua imagem com cabelos crespos e roupas pouco discretas, ao longo de sua trajetória, a postura imóvel de microfone na mão que aparece nessas duas primeiras passagens citadas se torna cada vez menos comum nos trabalhos da repórter.

Em 1982, por exemplo, a jornalista produziu uma reportagem sobre o voo duplo de asa delta e, para demonstrar o fato, voou ela mesma na carona de um piloto. Para fazer as imagens do voo, uma câmera foi colocada no bico da asa e, para equilibrar, duas pedras foram colocadas do outro lado ${ }^{9}$. Nas imagens, que enquadram de cima a repórter e o piloto, é possível acompanhar sua tensão no

9 A jornalista Glória Maria dá detalhes sobre a produção do trabalho nesta matéria do Esporte Espetacular: http://globoesporte.globo.com/programas/esporteespetacular/noticia/2011/09/gloria-maria-refaz-primeiro-voo-duplo-de-asa-delta-datelevisao-brasileira.html 
salto e sua expressão de alívio quando, finalmente, saem da rampa de voo e ganham os ares e Glória verbaliza: “Ufa! (...) É uma maravilha, depois da decolagem, essa corrida louca que dura menos de cinco segundos pela rampa, curtir o visual aqui da Pedra Bonita, é Fantástico."

Quando a relação com o factual deixa de ser fundamental na construção da matéria, Glória Maria costuma se apresentar, então, como uma repórter cuja ação é constituidora da construção jornalística. Em uma reportagem sobre a Chapada Diamantina, feita em 1987, a repórter, do alto da Cachoeira da Fumaça informa que "não dá pra ver sentado, nem em pé, pra olhar essa cachoeira, é só assim, tem que deitar, não é Luiz? Vamos lá. Dizem que é uma coisa impressionante, vamos ver se a gente consegue ver isso". A fala da repórter é coberta por imagens dela se deitando às margens de um despenhadeiro para observar a cachoeira e a imagem que se segue é da própria visão que se tem da cachoeira às bordas do despenhadeiro enquanto Glória Maria comenta em um tom de voz tão animado que chega a se aproximar de gritinhos: "Uh, é incrível! Nossa, é realmente maravilhoso, eu nunca vi uma coisa como essa". A voz off da repórter que se segue a esse comentário deixa ver que a fala anterior foi feita justamente no momento em que ela avista a cachoeira, registra o momento da ação, a reação que ela tem à situação. Assim, a ação de reportar algo é valorizada pela atuação do repórter e não necessariamente por uma relação com o factual, o presente do acontecimento. A performance menos convencional de Glória Maria observada aqui é uma característica que passa a distingui-la enquanto repórter e se torna contemporaneamente uma marca de sua atuação profissional. Atualmente no Globo Repórter, a jornalista é comumente lembrada por matérias em que pulou de bungee jump ${ }^{10}$, mostrou seu pavor ao subir em um camelo em pleno deserto ${ }^{11}$, fumou maconha com rastafáris na Jamaica e mostrou suas reações ${ }^{12}$ ao consumo da erva como parte do seu relato jornalístico.

Embora essa atuação marcada pelo relato da experiência não chame em causa a vivência subjetiva de Glória Maria como mulher negra, argumentamos que

10 Disponível em: <http://g1.globo.com/globo-reporter/videos/t/edicoes/v/gloria-maria-saltado-maior-bungeejump-do-mundo-em-macau/5930480/> Acesso em 10 abr. 2018.

11 Disponível em: <http://globotv.globo.com/rede-globo/memoria-globo/v/globo-reporter-omaoasis-da-paz2012/2422248/> Acesso em 10 abr. 2018.

12 Disponível em: <https://globoplay.globo.com/v/5135071/> Acesso em 10 abr. 2018. 
um olhar para sua trajetória enquanto repórter na televisão brasileira implica necessariamente a consideração de uma disputa acerca dos lugares possíveis para atuação de jornalistas negras na televisão brasileira e para as disputas implicadas na construção profissional dessas trajetórias. Como argumenta Sueli Carneiro (2019, p. 282),

Se partimos do entendimento de que os meios de comunicação não apenas repassam as representações sociais sedimentadas no imaginário social, mas também se instituem como agentes que operam, constroem e reconstroem no interior da sua lógica de produção os sistemas de representação, concluiremos que eles ocupam posição central na cristalização de imagens e sentidos sobre a mulher negra.

Destacamos que a atuação de Glória Maria enquanto uma repórter que se mostra como sujeito ativo do processo de produção jornalística além de ajudar a sustentar simbolicamente o espaço para a diferença no quadro de jornalistas da maior emissora de televisão do país, disputa uma noção de objetividade encarnada em corpos que personificam isenção e buscam sustentar uma prática institucional do jornalismo fundamentada em uma ideia de esfera pública na qual não caberiam impressões pessoais a respeito de uma experiência ou uma emoção. Enquanto experimenta aquilo que relata, Glória é um sujeito inteiro na tela, um sujeito feminino e negro.

Em uma edição recente do Globo Repórter na qual foi reprisado um debate promovido pelo programa Em Pauta do canal Globo News, Glória fez algo raro: falou, na função de jornalista e não de entrevistada, de sua experiência com o racismo. Naquela ocasião, ela, que é apresentadora do Globo Repórter, estava fora da função por conta de um tratamento de saúde e foi justamente essa a sua justificativa para não participar do debate que reuniu outras cinco jornalistas negras da Globo e da Globo News, além do jornalista negro Heraldo Pereira: Zileide Silva, Flávia Oliveira, Maria Júlia Coutinho, Aline Midlej e Lilia Ribeiro. 0 debate havia sido, originalmente, uma resposta a uma discussão sobre racismo feita pelo Em Pauta no dia anterior apenas com jornalistas brancos. Como resposta à repercussão do caso, no dia seguinte, abriu-se espaço para que os jornalistas negros da casa pudessem relatar suas experiências e fazer a sua abordagem do 
debate. Na reapresentação feita pela Globo Repórter, a fala de Glória introduziu o programa:

\begin{abstract}
Quem nasce orgulhosamente negro sabe muito bem o que são obstáculos. Então, como é que eu poderia ficar de fora desse momento tão especial do Globo Repórter? Como não apresentar essa conversa aberta e reveladora dos meus colegas? Vocês vão ver que tudo começa com uma pergunta: qual é a experiência dos meus amigos com o racismo no Brasil? E pra começar, eu vou contar um pouco da minha. Racismo é uma coisa que eu conheço, que eu vivi desde sempre. E a gente vai aprendendo a se defender, da maneira que pode. Eu tenho orgulho de ter sido a primeira pessoa no Brasil a usar a lei Afonso Arinos que punia o racismo não como crime, mas como contravenção. Eu fui barrada em um hotel por um gerente que disse que negro não podia entrar, chamei a polícia, e levei esse gerente de hotel aos tribunais. Ele foi expulso do Brasil, mas ele se livrou da acusação pagando uma multa ridícula porque o racismo no Brasil não vale nada, né? Só pra quem sofre o racismo. Mas isso é uma coisa que eu vou ter que viver ao longo da minha vida. 0 difícil pra mim agora é contar pras minhas filhas, explicar pra elas o que é o racismo em um momento em que elas estão assistindo a essas manifestações nos Estados Unidos e em vários países. Elas perguntam: 'mamãe, isso tudo está acontecendo, ele morreu, ele foi assassinado porque ele era negro?' E eu tenho que dizer, é, foi por isso. Mas eu espero que quando elas crescerem, elas agora estão com 11 e 12 anos, a gente esteja vivendo em um mundo melhor. Eu não sou muito otimista, mas eu acredito que um dia todo mundo vai ser visto como igual. Ninguém vai ser discriminado pela cor da pele. Tomara que as minhas filhas não precisem viver o que o negro vive hoje.
\end{abstract}

A fala de Glória, assim como o debate apresentado, quebra algo que se não chega a ser um silenciamento na televisão brasileira, é antes uma operação de poder que sustenta formas de opressão secularmente estabelecidas na sua cultura. Há muito se fala da falta de representação de pessoas negras nos espaços midiáticos, mas, para além da questão da representação em si, esse silêncio sustenta ainda “(...) velhos esquemas de expectativa e resposta, velhas estruturas de opressão, e esses devem ser alterados ao mesmo tempo que alteramos as condições de vida que são um resultado dessas estruturas(...)". (Lorde, 2019, p. 248) Entendemos, portanto, com Cidinha da Silva (2018, p. 260), que se hoje vemos um número cada vez maior de mulheres negras e feministas "ocupando espaços significativos na televisão, nos telejornais e nos portais de notícias, é 
porque foram beneficiadas pela luta das mulheres negras organizadas dos anos 1980 até os dias de hoje."

\section{Considerações finais}

O jornalismo ocidental moderno, fundamental para a sustentação de democracia tal como a concebemos classicamente, funda suas bases em uma ideia de objetividade que parece solidificar aquilo que Audre Lorde chama de institucionalização da rejeição da diferença (Lorde, 2019, p. 240). Na perspectiva adotada aqui, compreendemos o jornalismo enquanto uma instituição que se desenvolve em culturas específicas e que estabelece convenções que representam uma possibilidade do fazer jornalístico que estão em diálogo constante com mudanças mais amplas na história das culturas e sociedades. Assim, seus procedimentos, suas convenções e formas "antes de serem permanentes, neutros e a-históricos, estão articulados às tensões que regulam e perpassam o fazer jornalístico e que o inserem no tempo e na cultura." (LEAL, 2013, p. 26). Argumentamos, então, que a análise da trajetória profissional de Glória Maria como repórter - e sobretudo a recorrência de uma performance em que ela se apresenta como um sujeito constituído por dimensões mais amplas que sua faceta profissional - nos dá pistas importantes sobre a necessidade de pensar o jornalismo a partir de um novo quadro de referência, do questionamento mesmo das relações historicamente estabelecidas entre jornalismo, democracia e as dimensões de público e privado. Destacamos a presença disruptiva de Glória Maria enquanto uma mulher negra cuja atividade como repórter foi sempre pautada na ação pessoal como constituidora da narrativa jornalística. Ainda que as questões de raça tenham sido pouco pautadas em sua trajetória, a força da sua presença enquanto referência profissional e em momentos importantes da televisão brasileira, como a primeira transmissão a cores, encarna uma disputa fundamental para a instituição jornalística e suas bases ocidentais e modernas. 
Assim, compreendemos que a divisão de limites que se costuma estabelecer entre público e privado foi forjada, ao longo do tempo, na relação com disputas importantes sobre, por exemplo, aquilo que se atribui a um âmbito doméstico, relacionado historicamente a tarefas femininas; e um âmbito das esferas de decisão e poder relativas àquilo que é público, masculino. Para além de definir o que se costuma entender como assuntos que devem ou não ser discutidos pelo jornalismo - porque interessariam ao que é público -, essa divisão opera de modo mais cotidiano e cruel na crença de que os assuntos domésticos devem ser confinados aos espaços privados e nunca discutidos em público. Essas linhas de demarcação entre público e privado, definidas e acordadas na cultura e na sociedade a partir de normas e regras de conduta, como indica Dominique Mehl (2007), ainda que tenham sido sempre fluidas, permaneceram historicamente como um princípio de organização do debate público.

Desde os anos 1970, tem ganhado destaque no debate público questões relativas a um corpo entendido enquanto lugar de construção de um sujeito político, da subjetividade como lugar de apropriação de questões sociais e culturais por um sujeito cujo pessoal é construído também a partir de relações de poder (Foucault, 1979a, 1979b; Hall, 2009; Butler, 1993, 2004). 0 reconhecimento desse corpo político no qual se inscrevem marcas da vivência material dos sujeitos implica que o nosso olhar para o jornalismo seja orientado por uma reconfiguração das bases a partir das quais discutimos os limites entre público e privado que constituem a pauta jornalística, mas também, e sobretudo, sua dimensão de atuação enquanto instituição social que regula corpos e subjetividades constituindo identidades clivadas por um conjunto de normas. Como assinala Sueli Carneiro (2019, p. 273), “ao politizar as desigualdades de gênero, o feminismo transforma as mulheres em novos sujeitos políticos. Essa condição leva esses sujeitos a assumir, a partir do lugar em que estão inseridos, diversos olhares que desencadeiam processos particulares subjacentes na luta de cada grupo particular."

A trajetória de Glória como repórter da televisão brasileira deixa ver justamente uma disputa entre a conformação a um corpo desenhado pela objetividade que silencia diferenças como aquelas de raça e gênero, e a própria possibilidade de existência enquanto um corpo feminino e negro em um espaço de 
grande visibilidade midiática. Nesse cenário, ainda que sutis, as transformações se revelam como potência para a abertura de novos caminhos seja para a existência de outros corpos que disputem o padrão masculino e branco que é ainda hegemônico no jornalismo televisivo, seja para a transformação do próprio jornalismo como instituição e sua relação com uma esfera pública verdadeiramente democrática porque reconhecedora das diferenças.

\section{Referências bibliográficas}

ABRAM, Laís. Desigualdades de gênero e raça no mercado de trabalho brasileiro. Ciência e cultura, v. 58, n. 4, p. 40-41, 2006.

BRUSCHINI, Maria Cristina Aranha. Trabalho e gênero no Brasil nos últimos dez anos. Cadernos de Pesquisa. São Paulo, v. 37, n. 132, p. 537-572, Dez. 2007. Disponível em http://www.scielo.br/scielo.php?script=sci_arttext\&pid=S0100-

15742007000300003\&lng=en\&nrm=iso. Acesso em 29 Ago. 2020. https://doi.org/10.1590/S0100-15742007000300003.

BRUSCHINI, Cristina; LOMBARDI, Maria Rosa. Instruídas e trabalhadeiras: Trabalho feminino no final do século XX. Cadernos pagu, n. 17-18, p. 157-196, 2002.

BUTLER, Judith. Bodies that Matter: on the discursive limits of sex. London and New York: Routledge, 1993b.

Undoing Gender. London and New York: Routledge, 2004.

CARNEIRO, Sueli. Mulheres em movimento: contribuições do feminismo negro. In: HOLLANDA, Heloísa Buarque de. Pensamento feminista brasileiro: formação e contexto. Rio de Janeiro: Bazar dos Tempos, 2019.

CERQUEIRA, Daniel, et al. Atlas da Violência 2017. Rio de Janeiro: Ipea/ FBSP, 2017.

CHONG, Phillipa. Valuing subjectivity in journalism: Bias, emotions, and self-interest as tools in arts reporting. Journalism, v. 20, n. 3, p. 427-443, 2019. Disponível em: https://journals.sagepub.com/doi/abs/10.1177/1464884917722453\#articleCitationDow nloadContainer. Acesso em 29 Ago. 2020.

FOUCAULT, Michel. Les rapports de pouvoir passent à l'interieur des corps. In: FOUCAULT, Michel. Dits et écrits, v. 3, p. 1976-1979, 1979a.

Poder-Corpo. In: Foucault, Michel. Microfísica do Poder. Rio de Janeiro: Edições Graal, 1979b.

HALL, Stuart. Da Diáspora: Identidades e Mediações Culturais. Belo Horizonte: Editora UFMG, 2009. 
LEAL, Bruno Souza. 0 jornalismo à luz das narrativas: perspectivas e questões. LEAL, B; CARVALHO, C. (org.) Narrativas e poéticas midiáticas. São Paulo: Intermeios, 2013.

LORDE, Audre. Idade, raça, classe e gênero: mulheres redefinindo a diferença. In: HOLLANDA, Heloísa Buarque de. Pensamento feminista: conceitos fundamentais. Rio de Janeiro: Bazar dos Tempos, 2019.

NASCIMENTO, Beatriz. A mulher negra no mercado de trabalho. In: HOLLANDA, Heloísa Buarque de. Pensamento feminista brasileiro: formação e contexto. Rio de Janeiro: Bazar dos Tempos, 2019.

SACRAMENTO, Igor. Por um jornalismo televisivo de alto nível: as definições de qualidade na crítica especializada em duas décadas (1970/1980). VI Encontro Nacional de História da Mídia. Niterói, 2008.

SILVA, Cidinha da. De onde viemos: aproximações de uma memória. In: DE HOLLANDA, Heloisa Buarque. Explosão feminista: arte, cultura, política e universidade. Editora Companhia das Letras, 2018.

SANCHES, Solange. Trabalho doméstico: desafios para o trabalho decente. Revista Estudos Feministas, v. 17, n. 3, p. 879-888, 2009.

MEHL, Dominique. La télévision de l'intimité. In: French Cultural Studies, v. 18, n. 2, p. 153-167, 2007.

SANCHES, Neuza. A Brava Dama da Notícia. Veja, 20 de abril de 1994.

TÁVOLA, Arthur da. Maior presença de jornalistas no vídeo. O Globo, 03 de maio de 1979. 